los casos el hallazgo corresponda a una tumoración de gran tamaño, por lo cual la cirugía abierta es la técnica de elección. Sin embargo, en caso de tumores recidivantes o hallazgos incidentales, la resección lumboscópica es una alternativa eficaz para su manejo ${ }^{9,10}$.

B I B L I O G R A F Í A

1. Gaur D. Laparoscopic operative retroperitoneoscopy: Use of a new device. J Urol. 1992;148:1137.

2. Takatera H, Takaha M. Retroperitoneal schwannoma. Urology. 1986;28:529-31.

3. Arshad S, Girish D. Retroperitoneal schwannoma. BHJ. 2002.

4. White HR. Survival in malignant schwannoma. Cancer. 1971;27:720-9.

5. Regan JF, Juler GL, Scmutzer KJ. Retroperitoneal neurilemmoma. Am J Surg. 1977;134:140-5.

6. Goh B, Tan Y, Chung Y, Chow P, Ooi L, Wong W, et al. Retroperitoneal schwannoma. Am J Surg. 2006;192:14-8.

7. Heaton ND, Howard ER. Malignant retroperitoneal schwannoma. J R Soc Med. 1991;84:308-10.
8. Pollo C, Richard A, De Preux J. Résection d'un schwannome retroperitoneal en sablier par abord combiné. Neurochirurgie. 2004;50:53-6.

9. De Diego Rodríguez E, Roca Edreira A, Martín García B, Hernández Rodríguez R, Portillo Martín JA, Gutiérrez Baños JL, et al. Retroperitoneal benign schwannoma. Report of a new case. Actas Urol Esp. 2000;24:685-8.

10. Mir Maresma C, Raventós CX, Celma A, Bestard Vallejo J, Orsola de los Santos A, Morote Robles J, et al. Schwanoma retroperitoneal benigno, exéresis por laparoscopia. Actas Urol Esp. 2008;32:455-7.

P. Ávila Herrera ${ }^{\mathrm{a}, *}$, M. González Domínguez ${ }^{\mathrm{b}}$

O.F. Hernández Ordóñez ${ }^{\mathrm{b}}$ y J. Gutiérrez Aceves ${ }^{\mathrm{a}, \mathrm{b}}$

aServicio de Urología, Nuevo Hospital Civil, Guadalajara, Jalisco, México

${ }^{\mathrm{b}}$ Centro Médico Nacional La Raza, Instituto Mexicano del Seguro Social (IMSS), México, D. F., México

*Autor para correspondencia.

Correo electrónico: bpti@hotmail.com (P. Ávila Herrera).

\title{
Duplicación uretral: presentación de un caso clínico y revisión de la literatura médica
}

\section{Urethral duplication: case report and review of the literature}

\section{Sr. Director:}

Presentamos el caso de un paciente varón de 7 años de edad, con antecedentes personales de infecciones urinarias de repetición, que consultó por la presencia de un doble orificio a nivel del glande, uno en posición ortotópica y otro más dorsal. Refería la presencia de micciones por ambos orificios, siendo de mayor calibre el chorro procedente del orificio ortotópico, así como un goteo continuo. No relataba historia de instrumentación uretral. Se realizó una ECO renal, que resultó normal, y una cistouretrografía miccional seriada, que mostró una uretra accesoria dorsal completa hasta el cuello vesical (fig. 1). El trayecto principal se correspondía con la uretra ortotópica. Se exploraron ambos meatos uretrales con la introducción de una sonda de $10 \mathrm{Fr}$, observándose un buen paso de esta por los dos meatos. Se realizó una exéresis de la uretra dorsal accesoria, cursando el postoperatorio de forma favorable y con una evolución libre de infecciones urinarias.

La duplicación uretral es una anomalía que afecta mayoritariamente a varones y cuya incidencia es desconocida. Puede acompañarse de otras alteraciones genitourinarias (valvas de uretra posterior, reflujo vesicoureteral, displasia o agenesia renal, extrofia vesical), cardíacas, intestinales (ano imperforado, atresia de esófago), óseas, etc ${ }^{2,3}$. El desarrollo embriológico de la uretra se inicia hacia la tercera semana de gestación con la migración de las células mesenquimales desde la línea primitiva hasta la membrana cloacal originando los llamados pliegues cloacales, de los que derivarán los pliegues uretrales, los cuales hacia el final del tercer mes se cierran a modo tubular sobre la lámina uretral dando lugar a la uretra peneana. Este proceso se completa hacia el cuarto mes con la formación de la uretra glandular. Una noxa en esta

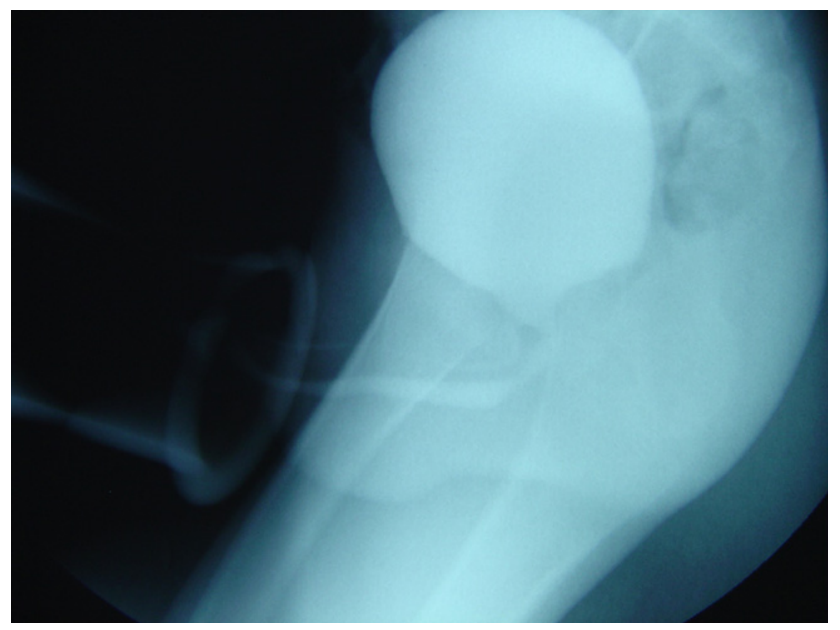

Figura 1 - Cistouretrografía miccional que muestra una uretra accesoria dorsal completa hasta el cuello vesical. 
secuencia sería el origen de la duplicación uretral. La mayoría de los pacientes se diagnostican en los primeros años de vida ${ }^{4}$. La forma de presentación clínica más frecuente es la existencia de un doble meato uretral y/o un doble chorro miccional. Otras manifestaciones descritas son la presencia de infecciones urinarias de repetición, reflujo vesicoureteral, incontinencia y goteo perineal durante la micción ${ }^{5}$. El diagnóstico se basa en la exploración física completada con la cistouretrografía miccional seriada y la uretrocistoscopia ${ }^{6}$. La ecografía ayuda al diagnóstico de otras posibles anomalías urinarias asociadas. Las diferentes variantes anatómicas se agrupan según la clasificación de Effmann ${ }^{1}$ en 3 tipos, con diferentes subtipos, siendo la más frecuente el tipo iA que no tiene comunicación ni con la uretra ni con la vejiga.

El caso presentado correspondería con el tipo IIA1 de la clasificación de Effmann, con dos uretras no comunicadas entre sí que se originan de forma independiente en la vejiga. El tratamiento debe ser individualizado en función de la variante anatómica y de la repercusión clínico-funcional. Salle et $\mathrm{al}^{3}$ propusieron un esquema terapéutico orientador cuyas opciones van desde la abstención terapéutica hasta la exéresis de la uretra dorsal accesoria, pasando por la meatoplastia aislada, la uretroplastia con colgajo o la resección endoscópica del tabique interpuesto entre ambas uretras.

En conclusión, la duplicación uretral es una rara anomalía urológica de origen desconocido y cuya presentación clínica varía en función del tipo anatómico de la malformación. Su diagnóstico puede pasar desapercibido, especialmente en pacientes que presentan otras anomalías asociadas como hipospadias o extrofia vesical. El tratamiento debe ser individualizado y abarca desde la abstención terapéutica hasta diferentes opciones quirúrgicas dependiendo de la variante anatómica.

B I B L I O G R A F Í A

1. Effmann EL, Lebowitz RL, Colodny AH. Duplication of the urethra. Radiology. 1976;119:179-85.

2. Woodhouse CR, Williams DI. Duplications of the lower urinary tract in children. Br J Urol. 1979;51:481-7.

3. Salle JLP, Sibai H, Rosenstein D, Brzezinski AE, Corcos J. Urethral duplication in the male: Review of 16 cases. J Urol. 2000;163:1936-40.

4. Podesta ML, Medel R, Castera R, Ruarte AC. Urethral duplication in children: Surgical treatment and results. J Urol. 1998;160:1830-3.

5. Psihramis KE, Colodny AH, Lewobitz RL, Retik AB, Bauer SB. Complete patent duplication of the urethra. J Urol. 1986;136: 63-7.

6. Chaumoitre K. Voiding cystourethrography in boys. Does the presence of the catheter during voiding alter the evaluation of the urethra? J Urol. 2004;171:1280-1.

I. Fernández-Pineda*, M.A. Fernández-Hurtado,

R. Barrero Candau y F. García Merino

Sección de Urología Pediátrica, Servicio de Cirugía Pediátrica, Hospital Infantil Universitario Virgen del Rocío, Sevilla, España

*Autor para correspondencia.

Correo electrónico: israfdez@hotmail.com

(I. Fernández-Pineda).

\section{Tumor testicular de células de Sertoli con marcadores neuroendocrinos positivos}

\section{Sertoli cell tumor of the testis with positive neuroendocrine markers}

\section{Sr. Director:}

Los tumores de células de Sertoli (TCS) representan menos del $1 \%$ de todas las neoplasias testiculares y se engloban dentro del grupo de los tumores de los cordones sexuales junto con los tumores de células de Leidyg, los tumores de la granulosa y los mixtos.

Presentamos el caso de un paciente varón de 69 años, sin antecedentes de interés, que acudió a nuestra consulta por presentar algia testicular izquierda intermitente de varios meses de evolución, con ausencia de clínica miccional. El dolor se encontraba localizado a nivel del polo superior del testículo izquierdo, sin llegar a palpar irregularidades, masas o engrosamientos anormales. Se realizó una ecografía en la que encontramos una lesión intratesticular de $1,5 \mathrm{~cm} \times 1 \mathrm{~cm}$, hipoecogénica, homogénea, localizada a nivel del polo superior del testículo izquierdo y rodeada por una delgada cápsula, sin guardar relación con el epidídimo u otras estructuras testiculares (sospecha de quiste epidermoide). El resto del órgano era normal así como el contralateral. Los marcadores tumorales (AFP, B-hCG y LDH) fueron negativos. A la luz de los datos clinicoradiológicos se realizó una tumorectomía con biopsia intraoperatoria, informada como lesión de características benignas con pulpa adyacente totalmente normal, optando por cirugía conservadora. El análisis anatomopatológico definitivo fue de tumoración bien delimitada, no encapsulada, rodeada de tubos seminíferos con espermatogénesis completa. Presentaba patrón de crecimiento difuso constituida por nidos sólidos (fig. 1) con estructuras tubulares y retiformes, sin atipia citológica ni 